Proc. of the X Int. Conf. - Ion Implantation and other Applications of Ions and Electrons, Kazimierz Dolny 2014

\title{
Thermal Desorption of Helium from Defected Silicon
}

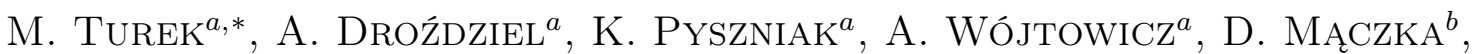 \\ Y. YUSCHKEVICH ${ }^{c}$, Y. VAGANOV ${ }^{c}$ AND J. ŻUK ${ }^{a}$ \\ ${ }^{a}$ Institute of Physics, Maria Curie-Skłodowska University in Lublin, \\ pl. M. Curie-Skłodowskiej 1, 20-031 Lublin, Poland \\ ${ }^{b}$ National Centre for Nuclear Research, A. Sołtana 7, 05-400 Otwock \\ ${ }^{c}$ Joint Institute for Nuclear Research, Joliot-Curie 6, 141980 Dubna, Moscow region, Russia
}

\begin{abstract}
The thermal desorption spectroscopy measurements of He implanted silicon samples are reported. The He implantation energy was $90 \mathrm{keV}$ (at $45^{\circ}$ tilt) while the fluence was $10^{16} \mathrm{~cm}^{-2}$. Additionally, the influence of $\mathrm{Si}$ pre-implantation (fluences in the range $10^{14}-10^{16} \mathrm{~cm}^{-2}, E=260 \mathrm{keV}$ ) was under investigation. The He releases from both interstitials/vacancies $(\beta$ peak) and cavities ( $\alpha$ peak or rather band consisting probably of at least two peaks) were observed. The $\alpha$ peak disappears for the pre-implantation fluences larger than $10^{15} \mathrm{~cm}^{-2}$, while $\beta$ peak becomes broader and shifts toward higher temperatures. The thermal desorption spectra were collected using heating ramp rates in the range $0.3-0.7 \mathrm{~K} / \mathrm{s}$. Desorption activation energy of the $\beta$ peak for different pre-implantation fluences was found using the Redhead analysis of the $\beta$ peak shift. It varies from $0.97 \mathrm{eV}$ for the sample that was not pre-implanted up to $1.3 \mathrm{eV}$ for the sample pre-implanted with the fluence $10^{16} \mathrm{~cm}^{-2}$.
\end{abstract}

DOI: 10.12693 /APhysPolA.128.849

PACS: $68.43 . \mathrm{Vx}, 61.72 . u f$

\section{Introduction}

Despite their very low reactivity, noble gases are known to be able to introduce important modification of the properties of solids [1] e.g. by forming bubbles (gas filled cavities) when introduced by high-fluence $\left(\approx 10^{16} \mathrm{~cm}^{-2}\right.$ or more) ion implantation. This process was initially studied in metals [2], but it also occurs in semiconductors. Formation of voids in silicon, the most important material for semiconductor industry, by He implantation was widely studied [3-8], as the buried layer of voids could be used e.g. for gettering of impurities $[9,10]$.

Thermal desorption spectrometry (TDS) was widely applied to study processes of void formation as well as He release from the Si matrix, focusing e.g. on factors as implantation temperature [6], annealing temperatures [4] or post-implantation parameters [5]. The typical TDS spectrum contains two peaks: one of them $(\beta)$ observed for lower temperatures and assigned to the release of $\mathrm{He}$ dissolved in Si (occupying vacancies and interstitials) and the other $(\alpha)$ corresponding to the release from the Hefilled voids. It should be also mentioned that several attempt have been made in order to model processes of gas filled voids formation as well as gas release [1, 11, 12].

In the above mentioned papers He implantation energies were either rather low (20 keV or less) [3-6] or in the $\mathrm{MeV}$ range $[7,8]$. The authors of the present paper decided to fill that gap and use energies typical of the implanter in the Institute of Physics, Lublin. Moreover, the influence of Si pre-implantation, which introduces different amounts of defects into the subsurface

*corresponding author; e-mail: mturek@kft.umcs.lublin.pl layers of the sample, on the TDS spectra has not yet, to the authors' knowledge, been tested.

The paper contains the brief description of the custommade equipment used for TDS measurements as well as experimental procedures. The Raman spectra of the preimplanted samples are presented to show the increasing (with the $\mathrm{Si}^{+}$fluence) amorphisation of the samples. The TDS spectra of He collected from the samples pre-implanted with different pre-implantation fluences are shown and discussed. The Redhead approach is applied to analyse the peak shift with the increasing heating ramp rate, which enables desorption activation energy calculations. The increase of activation energy corresponding to the $\beta$ peak with the Si pre-implantation fluence is shown.

\section{Experimental}

A construction of the TDS spectrometer was described in [13], here the basic facts are given for completeness. The cylindrical vacuum chamber containing the sample heater is connected to the quadruple mass spectrometer, vacuum meters, electrical feedthroughs and other equipment. The sample heater (HTR1002 Boralectric, Momentive, Strongsville OH, USA) is shielded by the molybdenum screens $(0.5 \mathrm{~mm}$ thick plates $)$, as well as $2 \mathrm{~mm}$ thick stainless steel screen at the bottom. The heater is powered by a programmable power supply EA-PS 8000T (EA-Electro-Automatik GmbH, Viersen, Germany), which enables the heating with different profiles and rates up to $\approx 1600 \mathrm{~K}$. Sample temperature is measured using the K-type thermocouple connected (via Hewlett-Packard 34970A data acquisition/switch unit) to the PC controlling the whole system. There is also an optional, contactless temperature measurement mode (using a pyrometer with the head mounted 
above the sample). The programmable power supply as well as the temperature measurement are controlled by custom-made software employing the PID algorithm [14]. The schematic view of the TDS spectrometer is shown in Fig. 1.

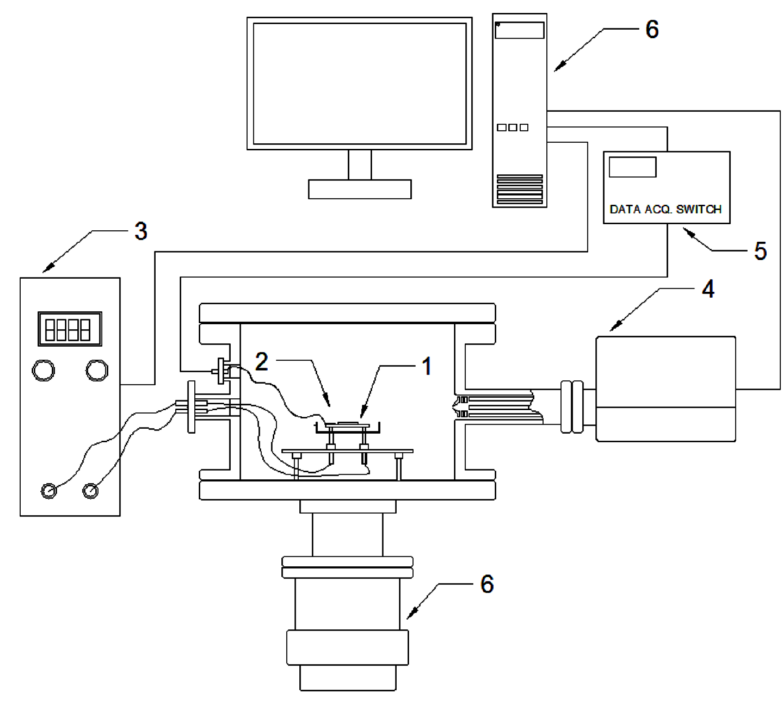

Fig. 1. Schematic view of the experimental setup: $1-$ sample heater, 2 - thermocouple, 3 - programmable power supply, 4 - quadruple mass spectrometer, 5 data acquisition switch, 6 - PC microcomputer.

The base pressure of $2 \times 10^{-7}$ mbar was maintained during all measurements using a turbomolecular pump. Helium released from the sample was detected by the QMG220 quadruple mass spectrometer (Pfeiffer Vacuum, Asslar, Germany) controlled by the Quadera ${ }^{\text {TM }}$ software.
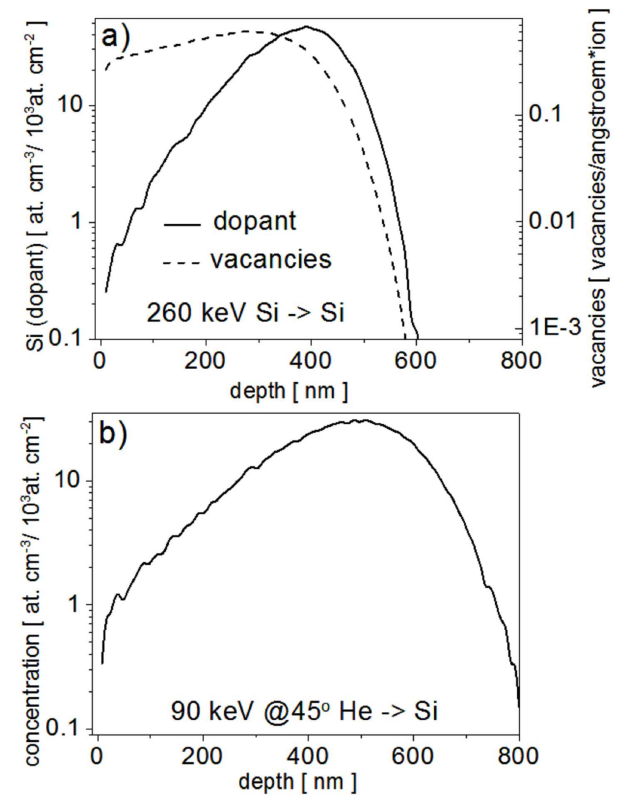

Fig. 2. Depth profiles of dopant and vacancies introduced into the Si sample during the pre-implantation (a) and depth profile of the implanted $\mathrm{He}(\mathrm{b})$. The results obtained using the SRIM code.

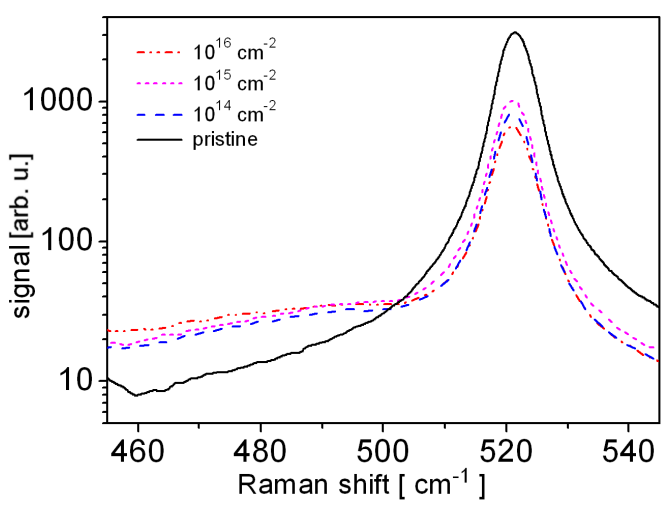

Fig. 3. Raman spectra of $\mathrm{Si}$ pre-implanted silicon samples.

The boron doped 100-oriented silicon wafers were first implanted with $\mathrm{Si}^{+}$ions using the ion implanter in the Institute of Physics, Lublin, equipped with the versatile arc discharge ion source with the evaporator [15-19]. The implantation energy was $260 \mathrm{keV}$ and the beam current density was maintained $\approx 1 \mu \mathrm{A} / \mathrm{cm}^{2}$. The three implantation fluences $\left(10^{14}\right.$ ions $/ \mathrm{cm}^{2}, 10^{15}$ ions $/ \mathrm{cm}^{2}$ and $10^{16}$ ions $/ \mathrm{cm}^{2}$ ) were chosen in order to introduce different amounts of defects into the subsurface layer of the sample. As it could be seen from the SRIM [20] results shown in Fig. 2a, the thickness of the defected layer is $\approx 400 \mathrm{~nm}$. Different degree of samples amorphisation is confirmed by the data in Fig. 3. It shows the Raman spectra obtained using the laser light wavelength of $514 \mathrm{~nm}$ for the pre-implanted and pristine samples. Measurements were done using a Renishaw Raman InVia Reflex Microscope. One can see increasing height of the amorphous silicon band near $480 \mathrm{~cm}^{-1}$ [21] while the crystalline silicon peak $(\approx 521 \mathrm{~nm})$ decreases with the pre-implantation fluence. The increase of amorphous silicon band for the fluence $10^{16}$ ions $/ \mathrm{cm}^{2}$ is rather surprisingly small (fluence of $10^{16}$ ions $/ \mathrm{cm}^{2}$ is expected to lead to full amorphisation), and will be subject of further studies using e.g. channeled Rutherford backscattering (RBS/C) spectroscopy.

The samples were then implanted with $\mathrm{He}^{+}$ions of $90 \mathrm{keV}$ energy incident at the angle of 45 degrees. The implantation parameters were chosen in order to introduce helium just below the defected layer (see Fig. 2b). The He depth profile partially overlaps the defected layer.

\section{Results}

The TDS spectrometer was baked out prior to the measurements in order to get rid as much as possible of residual gases. The sample was heated according to the isochronal scheme

$$
T(t)=T_{0}+\beta t,
$$

where $T_{0}$ is room temperature and $\beta$ is the heating ramp rate. The three different ramp rates were used: $0.3,0.5$, and $0.7 \mathrm{~K} / \mathrm{s}$. Additionally, $0.1 \mathrm{~K} / \mathrm{s}$ ramp rate was applied in the case of the pristine sample. The samples 
were heated up to $1300 \mathrm{~K}$. The mass spectrometer registered a signal corresponding to the mass of 4 a.m.u. (i.e. $\mathrm{He}$ ).

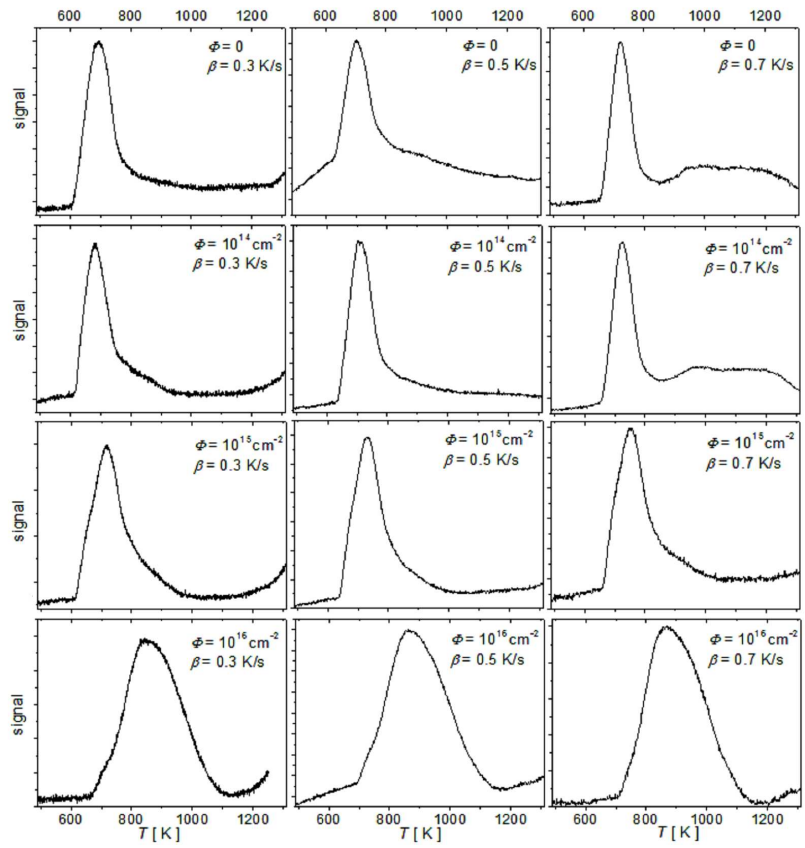

Fig. 4. TDS spectra of He released from $\mathrm{Si}$ samples measured using different heating ramp rates.

TABLE

Position of the $\beta$ peak and desorption activation energies for different pre-implantation fluences.

\begin{tabular}{|c|c|c|c|c|c|}
\hline$\beta[\mathrm{K} / \mathrm{s}]$ & $T_{p}[\mathrm{~K}]$ & $Q[\mathrm{eV}]$ & $\beta[\mathrm{K} / \mathrm{s}]$ & $T_{p}[\mathrm{~K}]$ & $Q[\mathrm{eV}]$ \\
\hline \multicolumn{3}{|c|}{$\Phi=0$ (pristine) } & \multicolumn{3}{|c|}{$\Phi=10^{14} \mathrm{~cm}^{-2}$} \\
\hline 0.7 & 720 & \multirow{4}{*}{$0.97 \pm 0.11$} & 0.7 & 723 & \multirow{4}{*}{$0.82 \pm 0.04$} \\
\hline 0.5 & 704 & & 0.5 & 706 & \\
\hline 0.3 & 694 & & 0.3 & 684 & \\
\hline 0.1 & 647 & & 0.1 & - & \\
\hline \multicolumn{3}{|c|}{$\Phi=10^{15} \mathrm{~cm}^{-2}$} & \multicolumn{3}{|c|}{$\Phi=10^{16} \mathrm{~cm}^{-2}$} \\
\hline 0.7 & 752 & \multirow{3}{*}{$1.0 \pm 0.23$} & 0.7 & 880 & \multirow{3}{*}{$1.3 \pm 0.13$} \\
\hline 0.5 & 731 & & 0.5 & 868 & \\
\hline $\begin{array}{l}0.3 \\
0.1\end{array}$ & $\begin{array}{c}716 \\
-\end{array}$ & & $\begin{array}{l}0.3 \\
0.1\end{array}$ & $\begin{array}{c}843 \\
-\end{array}$ & \\
\hline
\end{tabular}

The obtained TDS spectra are collected in Fig. 4. The $\beta$ peak, resulting from the release of He atoms dissolved in the bulk silicon (occupying vacancies and interstitials) and is observed for all samples. Its width is increasing with the Si pre-implantation fluence: from $\approx 100 \mathrm{~K}$ for the pristine $(\Phi=0)$ samples up to more than $200 \mathrm{~K}$ for the samples pre-implanted with the highest fluence. This is most probably the effect of energetic inhomogeneity of defects [5] introduced by $\mathrm{Si}^{+}$bombardment. Also a shift of the $\beta$ peak toward higher $T$ with $\mathrm{Si}^{+}$ fluence is observed - from $\approx 720 \mathrm{~K}$ for $\Phi=0$ up to $\approx 880$ for $\Phi=10^{16} \mathrm{~cm}^{-2}$ in the case of the samples heated with the highest ramp rate. Note that the $\beta$ peak positions for all samples are compared in the Table. The effect of $\beta$ peak shift with the Si fluence is observed for all ramp rates.

The shift of the $\beta$ peak with the changing ramp rate could be also observed, which is a typical behaviour and could be used to determine desorption activation energy employing the Redhead approach [22]. In the case of the first order process the Polanyi-Wigner equation has the form

$$
\frac{\mathrm{d} n}{\mathrm{~d} t}=-\gamma n \exp \left(-\frac{Q}{k T}\right),
$$

where $n$ is the surface density of the desorbing substance, $k$ is the Boltzmann constant, $Q$ is the desorption activation energy and $\gamma$ is the pre-exponential factor. Assuming the linear heating scheme and denoting the temperature corresponding to the maximum of the $\beta$ peak as $T_{p}$, one obtains from the condition $\mathrm{d}^{2} n / \mathrm{d} t^{2}=0$ the relationship

$$
\frac{1}{T_{p}}=\frac{k}{Q} \ln \left(\frac{T_{p}^{2}}{\beta}\right)+\frac{k}{Q} \ln \left(\gamma \frac{k}{Q}\right) .
$$

Henceforth, the diffusion activation energy could be obtained from the slope of the $1 / T_{p}$ vs. $\ln \left(T_{p}^{2} / \beta\right)$ plot. The calculation results for different $\mathrm{Si}^{+}$preimplantation fluences are also presented in the Table. One can see increase of the desorption activation energy of the $\beta$ peak with the amount of defects introduced by pre-implantation. The activation energy measured for the most defected sample is $\approx 30 \%$ higher than that of the pristine $(\Phi=0)$ sample. The measured values are close to those found in the literature $[1,5]$.

The release of He from cavities was also observed. There were rather low broad $\alpha$ bands instead of sharp and distinct peaks observed in [3-5]. The lower height of a peak obtained in the reported experiment could be explained by two facts: (i) the implantation fluence is twice smaller than that employed in [4, 5]; (ii) implantation energy is significantly higher than in $[4,5]$, hence the projected range is approximately twice as large. Both these facts lead to the conclusion that the number of He cavities per unit surface is much smaller during the reported experiments. Therefore, the signal from He release from cavities is weaker.

There is an open question whether the release from cavities is a single but very broad peak or rather two peaks centered at $\approx 950 \mathrm{~K}$ and $\approx 1150 \mathrm{~K}$. During the previous experiments a single $\alpha$ peak was always reported, though it was found for various temperatures $[1,3,6]$. The $\alpha$ release is observed for the fastest heating rate. Keeping in mind the asymmetric shape of $\beta$ peak for $\beta=0.5 \mathrm{~K} / \mathrm{s}$, one may suspect that a peak is shifted toward lower temperatures and partially corresponds to $\beta$ release. The $\alpha$ peak also disappears with the increasing $\mathrm{Si}$ pre-implantation fluence, it is invisible for $\Phi=$ $10^{15} \mathrm{~cm}^{-2}$. This could be due to the fact that the increasing disorder disturbs the internal well-defined facets [1] of He-filled cavities, lowering a potential barrier and, consequently, enabling He release at lower temperatures. 


\section{Conclusions}

The TDS measurements of helium released from the $\mathrm{He}^{+}$implanted $\left(E=90 \mathrm{keV}, 45^{\circ}\right.$ tilt) $\mathrm{Si}$ samples were presented. The Si samples were additionally preimplanted with $\mathrm{Si}^{+}$ions $(E=260 \mathrm{keV})$ with the fluences $10^{14} \mathrm{~cm}^{-2}, 10^{15} \mathrm{~cm}^{-2}$ and $10^{16} \mathrm{~cm}^{-2}$ in order to introduce different amounts of defects into the subsurface layer of $\approx 400 \mathrm{~nm}$ thickness. Two kinds of He release were found: one from He contained in vacancies/interstitials (peak $\beta$ ) and the other (peak $\alpha$ ) corresponding to the release from cavities. The $\alpha$ peak disappears for the samples defected using the Si fluences higher than $10^{15} \mathrm{~cm}^{-2}$. The release from cavities was observed as a separate (but very wide) peak only for the highest heating ramp rate $(0.7 \mathrm{~K} / \mathrm{s})$. The shape of the TDS spectra suggests that it is possible that the $\alpha$ release consist of more than one peak. This hypothesis has to be tested in detail using various heating rates and/or implantation energies. The width of $\beta$ peak increases with the Si pre-implantation fluence as the energetic inhomogeneity of the introduced defects rises. The changes of desorption activation energy of the $\beta$ peak with the Si pre-implantation fluence were determined applying the Redhead approach. The activation energy for the non-preimplanted sample is $0.97 \mathrm{eV}$ (good agreement with the literature data) and rises up to $1.3 \mathrm{eV}$ for $\Phi=10^{16} \mathrm{~cm}^{-2}$.

\section{References}

[1] A. Charaf Eddin, L. Pizzagalli, J. Phys. Condens. Matter 24, 175006 (2012).

[2] H. Trinkaus, B.N. Singh, J. Nucl. Mater. 323, 229 (2003).

[3] C.C. Griffioen, J.H. Evans, P.C. De Jong, A. van Veen, Nucl. Instrum. Methods Phys. Res. B 27, 417 (1987).

[4] F. Corni, G. Calzolari, F. Gambetta, C. Nobili, R. Tonini, M. Zapparoli, Mater. Sci. Eng. B 71, 207 (2000).

[5] G.F. Cerofolini, G. Calzolari, F. Corni, S. Frabboni, C. Nobili, G. Ottaviani, R. Tonini, Phys. Rev. B 61 10183 (2000).
[6] E. Oliviero, M.L. David, M.F. Beaufort, J.F. Barbot, A. van Veen, Appl. Phys. Lett. 81, 4201 (2002).

[7] S. Godey, E. Ntsoenzok, T. Sauvage, A. van Veen, F. Labohm, M.F. Beaufort, J.F. Barbot, Mater. Sci. Eng. B 73, 54 (2000).

[8] P. Desgardin, M.-F. Barthe, E. Ntsoenzok, C.-L. Liu, Appl. Surf. Sci. 252, 3231 (2006).

[9] V. Raineri, P.G. Fallica, G. Percolla, A. Battaglia, M. Barbagallo, S.U. Campisano, J. Appl. Phys. 78, 3727 (1995)

[10] V. Raineri, M. Saggio, E. Rimini, J. Mater. Res. 15, 1449 (2000).

[11] M. Hasanuzzaman, Y.M. Haddara, A.P. Knights, J. Appl. Phys. 112, 054909 (2012).

[12] L. Pizzagalli, M.L. David, M. Bertolus, Modelling Simul. Mater. Sci. Eng. 21, 065002 (2013).

[13] A. Drozdziel, A. Wojtowicz, M. Turek, K. Pyszniak, D. Maczka, B. Slowinski, Y.V. Yushkevich, J. Zuk, Acta Phys. Pol. A 125, 1400 (2014).

[14] K. H. Ang, G. Chong, IEEE Transactions on Control Systems Technology, 13, 559 (2005).

[15] M. Turek, S. Prucnal, A. Droździel, K. Pyszniak, Nucl. Instrum. Methods Phys. Res. B 269, 700 (2011).

[16] M. Turek, A. Droździel, K. Pyszniak, S. Prucnal, D. Maczka, Yu. Yushkevich, Yu.A. Vaganov, Instrum. Exp. Tech. 55, 469 (2012).

[17] M. Turek, A. Droździel, K. Pyszniak, S. Prucnal, Nucl. Instrum. Methods Phys. Res. A 654, 57 (2011).

[18] M. Turek, S. Prucnal, A. Droździel, K. Pyszniak, Rev. Sci. Instrum. 80, 043304 (2009).

[19] M. Turek, A. Droździel, K. Pyszniak, S. Prucnal, J. Żuk, Przeglad Elektrotechniczny 86, 193 (2010) (in Polish).

[20] J.F. Ziegler, M.D. Ziegler, J.P. Biersack, Nucl. Instrum. Methods Phys. Res. B 268, 1818 (2010).

[21] J.S. Lannin, L.J. Pilione, I. Kshirsagar, R. Messier, R.C. Ross, Phys. Rev. B 26, 3506 (1982).

[22] P.A. Redhead, Vacuum 12, 203 (1962). 